\title{
POSSÍVEL INFLUÊNCIA DO FENÔMENO CLIMÁTICO OCEÂNICO- ATMOSFÉRICO EL NIÑO OSCILAÇÃO SUL (ENOS) SOBRE A PRECIPITAÇÃO ACUMULADA MENSAL OBSERVADA EM CAMPOS DOS GOYTACAZES - RJ, BRASIL
}

\author{
Antônio Ivo Gomes Barbosa ${ }^{(a)}$, Eduardo Manuel Rosa Bulhões (b) \\ (a) Departamento de Geografia, Universidade Federal Fluminense, antonioivo@id.uff.br \\ (b) Departamento de Geografia, Universidade Federal Fluminense, eduardobulhoes @id.uff.br
}

\section{Eixo: Climatologia em Diferentes Níveis Escalares: Mudanças e Variabilidades}

\begin{abstract}
Resumo/
O estudo se baseia na hipótese de existir alguma relação entre o ENOS e os valores de precipitação acumulada mensal em Campos dos Goytacazes - RJ entre 1961 e 2016. Foram analisadas seis estações distribuídas no município, utilizando para isto o banco de dados fornecidos pela NOAA onde é possível observar valores de TSM na porção sul-oriental do Oceano Pacífico, de modo a identificar os períodos de ocorrência do ENOS e relacioná-los com os dados climatológicos de precipitação acumulada mensal do município, cedidos por duas plataformas online: BDMEP, desenvolvida pelo INMET; e HidroWEB, desenvolvida pela ANA. Foi elaborada uma planilha onde, após análise estatística, não foi possível obter clara evidência de correlação entre tais variáveis. Entretanto, estudos devem continuar sendo realizados para uma melhor compreensão acerca do ENOS e seus possíveis efeitos na região sudeste brasileira, visto que isso ainda não está muito claro para a comunidade científica.
\end{abstract}

Palavras chave: ENOS, Precipitação, Campos dos Goytacazes.

\section{Introdução}

Sabe-se que: "O estudo do tempo e do clima ocupa uma posição central e importante no amplo campo da ciência ambiental" (AYOADE, 2012, p. 1). A biosfera, hidrosfera e litosfera são influenciadas diretamente ou indiretamente pelos processos atmosféricos (Ayoade, 2012), e essa é uma das razões pelas quais o estudo do tempo e do clima se fazem tão importantes nos dias atuais. O fato é que o estudo climatológico e meteorológico sempre foi importante para o decorrer das atividades humanas ao longo dos mais diversos períodos históricos já vivenciados. Enquanto que o tempo meteorológico pode ser definido como um estado físico das condições atmosféricas em um determinado momento e local, o clima pode ser compreendido como um estudo médio do tempo para o determinado período ou mês em uma certa localidade, se referindo assim a características da atmosfera inseridas das observações contínuas durante um determinado período, incluindo considerações estatísticas sobre os desvios em relação às médias e frequências de eventos que ocorrem em determinada condição do tempo (INMET, 2016). 


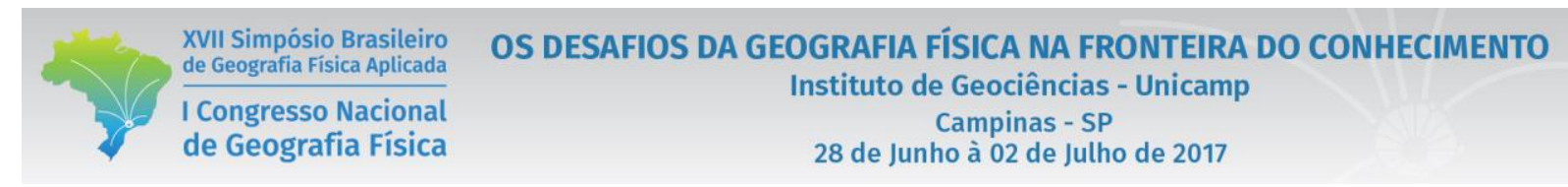

Uma observação climatológica pode identificar períodos de oscilações de padrões climáticos. Todavia, o que se denomina mudanças climáticas pode ser caracterizado, na verdade, por anomalias climatológicas que podem influenciar a variabilidade usual do clima de algumas regiões de maneira direta ou indireta, o que causaria implicações relacionadas ao âmbito socioeconômico destas localidades. Uma dessas anomalias climatológicas denomina-se El Niño Oscilação Sul (ENOS). Registros paleoclimáticos, históricos, arqueológicos e relatos de navegadores apontam que o ENOS tem sido capaz de modificar os padrões climatológicos em diversas localidades do continente americano há mais de quinhentos anos. Ocorrem então mudanças nas forças dos ventos, transformações na quantidade e intensidade de chuvas, secas, enchentes, atividade pesqueira e modificações nas taxas de produção agrícola. É possível que este fenômeno estivesse relacionado até mesmo com a crise agrícola que ajudou na decadência da civilização Maia, quando observamos estudos sobre variabilidade climática no campo da paleoclimatologia (Loiola, 2012). Estudos acerca do ENOS não teriam sido possíveis de serem realizados se não fosse pela descoberta feita por Sir Gilbert Walker. De acordo com Steinke (2012, p. 119):

(...) foi no ano de 1924 que o inglês Gilbert Walker identificou uma grande variação de pressão atmosférica entre as massas de ar localizadas nas faixas tropicais e subtropicais dos oceanos Índico e Pacífico. Essa variação indicava que, sempre que um sistema de baixa pressão (centro ciclonal associado a convecção e chuva) estivesse atuando na região de Darwin, na Austrália, um sistema de alta pressão (centro anticiclonal associado a subsidência) era detectado na costa do Peru. Esta pode ser considerada a situação normal da circulação zonal.

Neste contexto, torna-se impossível falar do ENOS sem que fosse feita uma análise perante a base conceitual e cientifica da Célula de Walker, também conhecida como Circulações de Walker. De acordo com Barry e Chorley (2013, p. 185), estas células ou circulações:

Representam componentes zonais (leste-oeste) de grande escala do fluxo de ar tropical. Essas circulações zonais são movidas por grandes gradientes de pressão no sentido lesteoeste causados por diferenças no movimento vertical. Por um lado, o ar ascende sobre os continentes aquecidos e as partes mais quentes dos oceanos; por outro, o ar desce sobre partes mais frias dos oceanos, sobre áreas continentais onde sistemas profundos de alta pressão se estabeleceram, e em associação com células de alta pressão subtropicais. Sir Gilbert Walker identificou essas circulações em 1922-1923, com sua descoberta de uma correlação inversa entre a pressão sobre o Oceano Pacífico oriental e a Indonésia. A intensidade e a fase dessa chamada Oscilação Sul costumam ser medidas pela diferença de pressão entre o Taiti $\left(18^{\circ} \mathrm{S}, 150^{\circ} \mathrm{W}\right)$ e Darwin, na Austrália $\left(12^{\circ} \mathrm{S}, 130^{\circ} \mathrm{E}\right)$. O índice de Oscilação Sul (Southern Oscilation Index - SOI) tem duas fases extremas: positiva, quando existe uma forte alta pressão no Pacífico Sudeste e uma baixa centrada sobre a Indonésia, com ar ascendente e precipitação convectiva; e negativa (ou baixa), quando a área de baixa pressão e convecção é deslocada para leste em direção à Linha Internacional de Mudança de Data.

O objetivo deste trabalho traduz-se em analisar como o clima no município de Campos dos Goytacazes RJ se comportou perante as oscilações climáticas anômalas em escala global, no que se refere ao 
fenômeno ENOS e suas implicações nos valores de precipitação acumulada mensal observados nesta localidade ao longo de 55 anos.

\section{Metodologia}

A estratégia metodológica distribuiu-se pelos seguintes atributos correspondentes ao método: Pesquisa exploratória e pesquisa descritiva dos materiais encontrados, compreendidos em: leitura, interpretação e análise dos materiais obtidos. Posteriormente, foram obtidos os dados registrados pelas estações climatológicas e pluviométricas do município de Campos dos Goytacazes - RJ para que pudesse ser feita análise estatística para que se obtivessem possíveis relações entre o que foi observado e a ocorrência do ENOS ao longo do espaço temporal aqui definido, correspondente entre os anos de 1961 e 2016 . Os pontos de coleta de dados foram: Estação 83698, localizada no Aeroporto Bartolomeu Lisandro, nas coordenadas $21^{\circ} 42^{\prime} 00^{\prime}$ 'S e $41^{\circ} 18^{\prime} 15^{\prime}$ 'W, cujo banco de dados foi disponibilizado pelo BDMEP (Banco de Dados Meteorológicos para Ensino e Pesquisa); Estação 2141002, localizada na Ponte Municipal, nas coordenadas $21^{\circ} 45^{\prime} 00^{\prime \prime} \mathrm{S}$ e $41^{\circ} 18^{\prime} 00^{\prime \prime W}$; Estação 2141022, localizada na zona central da cidade, nas coordenadas $21^{\circ} 45^{\prime} 00^{\prime}$ 'S e $41^{\circ} 19^{\prime} 48^{\prime \prime} \mathrm{W}$; Estação 2141026, localizada no ponto mais ao norte, no distrito

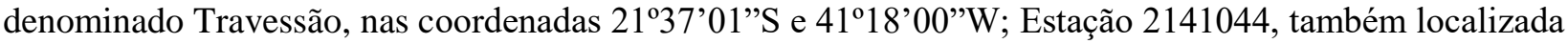
na zona central da cidade, nas coordenadas $21^{\circ} 45^{\prime} 00^{\prime \prime S}$ e $41^{\circ} 19^{\prime} 48^{\prime \prime} \mathrm{W}$; e a Estação 2241001, localizada no ponto mais à sudeste, no distrito denominado Farol de São Tomé, nas coordenadas 2202'24"S e 41 $03^{\circ} 18^{\prime \prime} \mathrm{W}$. Adicionalmente, obtiveram-se dados quantitativos referentes aos anos em que foram observadas anomalias na temperatura da superfície do mar (TSM) no Oceano Pacífico, disponibilizados pela National Oceanic and Atmospheric Administration (NOAA), relacionando-os com os valores de precipitação acumulada mensal das estações climatológicas e pluviométricas do município, onde por fim foi possível elaborar uma correlação estatística entre tais variáveis e uma tabela de contingência com os valores observados, para que pudesse concluir a existência (ou não) de alguma relação entre essas variáveis, concluindo desta forma o objetivo deste trabalho.

\section{Resultados e Discussão}

Após a análise dos dados, obteve-se um coeficiente de correlação de - 0,0851 entre os valores referentes ao ENOS e os valores médios de precipitação acumulada mensal no município de Campos dos Goytacazes. Devido à proximidade deste valor com o zero, isto significa que, mediante ao que foi analisado, não foi possível obter uma relação estatística entre a incidência dos fenômenos climatológicos El Niño e La Niña com os acúmulos de chuva em Campos dos Goytacazes, no período que correspondeu entre os anos de 


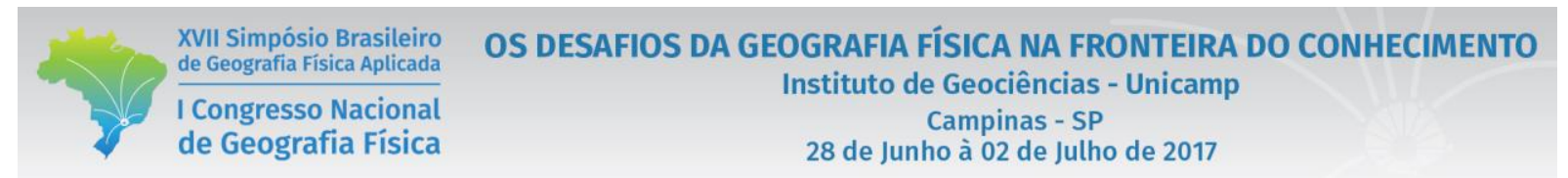

1961 e 2016. No entanto, vale lembrar que isso não significa que não haja uma relação entre estas duas variáveis, mas que precisamente neste espaço temporal analisado não houve tal relação.

Uma vez obtido o coeficiente de correlação, foi possível comprovar o seu significado por meio da elaboração de um diagrama de dispersão. Entretanto, algo interessante ocorre se analisarmos a linha de correlação linear gerada pelo diagrama de dispersão, que corresponde à Figura 1.

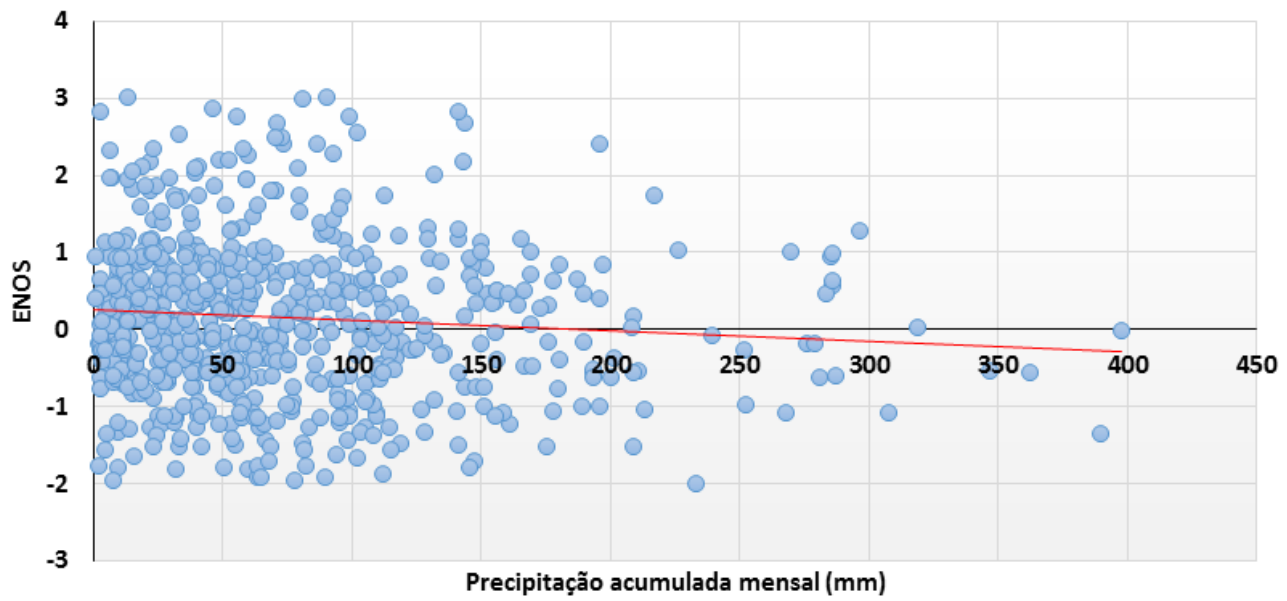

Figura 1 - Diagrama de dispersão ENOS e a precipitação acumulada mensal média no município de Campos dos Goytacazes, RJ - Brasil, cuja linha em vermelho representa a linha de correlação linear.

Percebe-se que existe uma relação linear negativa ou inversa entre os valores de ENOS e os valores de precipitação acumulada mensal. Isto significa que, ao menos em termos estatísticos, há uma leve tendência que anos em que predominem La Niña gerem acúmulos de precipitação mensal mais elevados no município de Campos dos Goytacazes - RJ. Porém, não se pode compreender isto como uma regra geral, uma vez que essa linha de correlação linear encontra-se próxima do eixo horizontal central do gráfico.

Somando-se a isso, após uma análise detalhada entre os valores observados, foi possível criar uma tabela de contingência entre observações ENOS e distribuição de frequência dos valores de precipitação acumulada mensal, conforme constatado a seguir, correspondente à Tabela I:

Tabela I - Tabela de contingência entre observações ENOS e distribuição de frequência dos valores de precipitação acumulada mensal entre 1961 e 2016.

\begin{tabular}{r|cccc|c}
\hline \multirow{2}{*}{ ENOS } & \multicolumn{5}{|c}{ Precipitação (mm) } \\
\cline { 2 - 6 } & $\mathbf{1 ~ a ~ 1 0 0}$ & $\mathbf{1 0 1}$ a 200 & $\mathbf{2 0 1}$ a 300 & $\mathbf{3 0 0}$ & Total \\
\hline La Niña & 123 & 39 & 9 & 4 & 175 \\
Normal & 191 & 55 & 8 & 2 & 256 \\
El Niño & 183 & 42 & 8 & 0 & 233 \\
\hline Total & $\mathbf{4 9 7}$ & $\mathbf{1 3 6}$ & $\mathbf{2 5}$ & $\mathbf{6}$ & $\mathbf{6 6 4}$ \\
\hline
\end{tabular}




\section{Conclusões}

Os eventos ENOS não possuem uma relação significativa com os valores de precipitação acumulada mensal no município de Campos dos Goytacazes, RJ - Brasil - ao menos entre os anos de 1961 e 2016. Entretanto, futuros estudos talvez possam encontrar evidências mais significativas envolvendo outros fatores ou elementos climatológicos (tais como temperatura, velocidade e direção dos ventos, pressão atmosférica e umidade), buscando suas relações com a predominância de eventos ENOS que ocorrem na porção oriental do Pacífico Sul. Propõe-se que tais estudos possam também abranger o conteúdo de séries temporais (o clima é uma série temporal), podendo ser elaborada uma análise de variância e comparação entre as médias das variáveis a serem utilizadas, assim como dar procedência à obtenção de uma correlação para variáveis discretas.

\section{Agradecimentos}

Agradeço ao Professor Dr. Eduardo Manuel Rosa Bulhões pela orientação, credibilidade e confiança em meu compromisso com a ciência, e ao Professor Dr. Gustavo Henrique Naves Givisiez pelo apoio na elaboração do conteúdo estatístico. Ambos jamais deixaram de acreditar que eu seria capaz de trabalhar de forma resiliente, demonstrando dedicação e vontade de alcançar os objetivos, superando assim os desafios diários que a vida nos propõe. Agradeço ao V SBGFA, por me possibilitar esta grande oportunidade de divulgar o nosso trabalho em meio à comunidade científica. Por fim, agradeço àquele que criou tudo o que existe, por me proporcionar momentos tão grandiosos em minha carreira.

\section{Referências}

AYOADE, J. O.. Introdução à Climatologia para os Trópicos. 16. ed. Rio de Janeiro: Bertrand Brasil, 2012. 350 p. Tradução de Maria Juraci Zani dos Santos; revisão de Suely Bastos; coordenação editorial de Antonio Christofoletti.

BARRY, Roger G.; CHORLEY, Richard G.. Atmosfera, Tempo e Clima. 9. ed. Porto Alegre: Bookman, 2013.

INMET - Instituto Nacional de Pesquisas Espaciais, 2016. Disponível em <http://www.inmet.gov.br/portal/>. Acesso em 24/11/2016.

LOIOLA, Sérgio Almeida. ADAPTAÇÃO AOS CENÁRIOS IMPONDERÁVEIS DA VARIABILIDADE CLIMÁTICA. Terceiro Incluído, Goiás, v. 2, n. 1, p.86-110, 6 set. 2012. Universidade Federal de Goias. http://dx.doi.org/10.5216/teri.v2i1.20472.

Disponível

em:

$<$ https://www.revistas.ufg.br/teri/article/viewFile/20472/11946>. Acesso em: 24 nov. 2016.

STEINKE, Ercília Torres. Climatologia Fácil. São Paulo: Oficina de Textos, 2012.

BDMEP. Banco de dados meteorológicos para ensino e pesquisa. Disponível em: $<$ http://www.inmet.gov.br/projetos/rede/pesquisa/>. Acesso em: 21/10/2016.

ANA. Agência Nacional de Águas. Disponível em: <http://www.snirh.gov.br/hidroweb/>. Acesso em: 21/10/2016.

DOI - 10.20396/sbgfa.v1i2017.2466 - ISBN 978-85-85369-16-3 